\title{
Pelanggaran Maxim Dalam Novel Asal Kau Bahagia Karya Bernard Batubara
}

\author{
Prapti Wigati Purwaningrum \\ Universitas Bina Sarana Informatika \\ e-mail : prapti.pwp@bsi.ac.id
}

\author{
Cara Sitasi : \\ Purwaningrum, P. W. (2019). Pelanggaran Maxim Dalam Novel Asal Kau Bahagia Karya Bernard Batubara. \\ 2Wanastra, 11(2), 107-112.
}

\begin{abstract}
The purposes of this study is to describe what and how the Flouts exploiting maxims of the cooperative principle in the dialogues "Asal Kau Bahagia" novel by Bernard Batubara. The approach of this study is qualitative with the content analysis method because this study prioritizes the content approach of the dialogues in the novel. The writer choses this novel because the storyline is simple, easy to understand, and lead the reader imagination especially what Radha experienced when He seemed to be losing his grip on life. In addition, in it there are many dialogues that flouts exploiting maxims of cooperative principle. This research is focused on speech which contains Flouts exploiting maxims and its implications that are adjusted based on the context in the story. Some of the theories used in this study include Implicature theory by Grice, and the principle of relevance by Sperber \& Wilson. The conclusion of this study is the writer found 16 data which contained fouts exploiting maxims in cooperative principle. From these data, the most Flouts exploiting maxim of quality and quantity occurred in each of 6 data, Flouts exploiting maxim of reevance consist of 8 data, Flouts exploiting maxim of manner 3 data. Flouts exploiting maxims occur in this novel include the purposes of hiding a secret, giving an explanation, insinuating, asking for an excuse, distracting the opponent's speech, and face saving acts of the speaker and also the hearer.
\end{abstract}

Keywords: Pragmatic, implicature, Flouts exploiting maxims .Asal Kau Bahagia Novel by Bernard Batubara

\section{PENDAHULUAN}

Saat ini novel masih menjadi salah satu jenis bacaan yang memiliki banyak peminat. Berbagai genre novel hadir siap memanjakan pembacanya. Alur cerita yang ringan, penuh dengan imajinasi menjadi daya tarik tersendiri pada sebuah novel untuk dinikmati. Novel yang berjudul "Asal Kau Bahagia" karya Bernard Batubara menjadi salah satu novel yang diadaptasi dari lagu dengan judul yang sama dari grup band Armada .

Novel ini mengisahkan tentang cerita cinta antara Radha dan Tasya yang sudah terjalin cukup lama. Sejak awal Radha selalu diselimuti keraguan akan perasaan Tasya padanya. Hal ini dilatarbelakangi dengan perbedaan diantara keduanya, Radha pria yang biasa saja dengan wajah tidak terlalu tampan, sedangkan Tasya cewe populer di sekolah. Banyak pria yang ingin berlahub dihatinya, namun Taysa memilih radha sebagai kekasihnya. Hingga suatu ketika Radha mengalami kecelakaan yang membuatnya koma dan mengalami hal-hal diluar logika. Kejadian tersebut menjawab atas semua keraguan Radha atas perasaan Tasya selama ini. Ternyata Tasya menjalin cinta dengan sosok selain Radha. Hal ini membuat perasaan Radha hancur, namun sebelum ajal menjemput Radha, Ia mengikhlaskan Tasya untuk menemukan cinta lain,
"Asal Tasya lebih merasa bahagia" dengan sosok lain tersebut. Radha pergi dengan tenang.

Dalam mengisahkan setiap alur ceritanya tidak lepas dari tuturan yang dituturkan oleh setiap karakter dalam novel tersebut. Ada tuturan yang maksud tuturannya dituturkan secara langsung, tetapi tidak jarang juga pada beberapa tuturan yang banyak mengisyaratkan maksud lain. Hal inilah yang terkadang menjadi hal yang menarik bagi pembaca karena harus mampu mencerna atau menarik maksud dari tuturan tersebut, dalam novel tersebut banyak sekali terjadi pelanggaran maksim yang mengakibatkan munculnya implikatur

Implikatur adalah makna dari balik sebuah tuturan, implikatur muncul karena adanya pelanggaran maksim. Maksud dari sebuah tuturan terkadang tidak dituturkan melainkan hanya tersirat, sehingga memerlukan pemahaman lebih untuk dapat memperoleh makna yang sebenarnya. Dengan latar belakang di atas, penulis ingin fokus pada implikatur yang ada pada beberapa tuturan dan dikaitkan dengan teori relevansi, dengan demikian penulis ingin mengetahui maksud dari masing-masing implikatur yang muncul dalam percakapan para karakter dalam Novel "Asal Kau Bahagia " Menurut (Sperber, D and Wilson, 1995) mengemukakan bahwa dalam sebuah percakapan hanya dibutuhkan 
tuturan yang relevan agar komunikasi berjalan dengan lancar. Dalam teori ini tuturan penutur dianggap relevan jika terdapat efek kontekstual yaitu dengan adanya informasi baru berkaitan dengan informasi lama sehingga tuturan penutur dapat diterima oleh petutur. Berikut beberapa teori yang akan mendukung dalam penulisan ini.

\section{Pragmatik}

Menurut gazdar dalam (Nadar, 2009)pragmatic adalah kajian antara lain mengenai deiksis, implikatur, presuposisi, tindak tutur, dan aspekaspek struktur wacana. Pendapat lain juga diungkapkan oleh (Purwo, 1984) Pragmatik sebagai telaah mengenai makna tuturan melalui sebuah konteks. Melalui pragmatik pembaca tidak hanya sekedar mengetahui makna tersurat tetapi juga makna tersirat dari tuturan yang erat kaitannya dengan konteks pada saat tuturan tersebut dituturkan.

\section{Aspek tutur}

Menurut Leech Aspek tutur meliputi penutur, lawan tutur, tujuan tutur, tuturan sebagai produk tindak verbal. Terkait dengan aspek tutur penutur dan lawan tutur ditegaskan bahwa lawan tutur atau petutur adalah orang yang menjadi sasaran tuturan dari penutur.

\section{Implikatur}

(Grice, 1975) berpendapat bahwa agar percakapan dapat berjalan secara efisien, tidak membuangbuang waktu dan tenaga maka penutur harus mematuhi Prinsip Kerja Sama (PKS), yang dikenal dengan 4 Maksiml:

1. Maksim kuantitas, buatlah percakapan seinformatif mungkin sesuai yang diperlukan dan jangan melebih-lebihkan informasi yang diperlukan.

2. Maksim kualitas, jangan katakana apa yang menurut anda tidak benar dan jangan katakana sesuatu yang tidak ada bukti.

3. Maksim relasi, berikan ujaran yang relevan atau nyambung

4. Maksim cara, hindari ambiguitas, ungkapkan secara singkat, dan runtut.

\section{Jenis-Jenis implikatur percakapan}

Grice membedakan dua macam implikatur atau makna tersirat itu, Keduanya adalah implikatur konvensional dan implikatur non-konvensional atau implikatur percakapan.

Contoh:
1. Implikatur konvensional "Bahkan Bapak Dekan menghadiri ulang tahun saya"

Implikatur konvensional ujaran tersebut adalah bahwa bapak dekan biasanya tidak menghadiri ulang tahun saya.

2. Implikatur non-konvensional atau implikatur percakapan
A : Maukah anda menghadiri acara selamatan ulang tahun saya?
B : Saya kebetulan ke Amerika selama sebulan dan berangkat besok

Yang tersirat dari jawaban tersebut jawaban tidak. Namun jawaban ini tidak diberikan secara terus terang. Jika seseorang pergi ke luar negeri, ia tidak berada di Jakarta maka ia tidak dapat menghadiri selamatan yang dimaksudkan.

Dalam keseharian, ternyata tidak semua tuturan atau jawaban dari sebuah pertanyaan diujarkan dengan mematuhi PKS, hal ini dikarenakan perlu menjaga hubungan social. Ketidakpatuhan kita kepada PKS Grice karena perlu menjaga muka. Dengan adanya pelanggaran maksim maka penutur mengemas tuturanya dalam tuturan tidak langsung atau tersirat, dalam pragmatik dikenal dengan istilah implikatur. Penggunaan implikatur atau penuturan tuturan secara tidak langsung memiliki motivasi agar dapat mengurangi dampak daya ujarannya. Hal ini tejadi bila ujaran berpotensi mengancam muka penutur maupun petutur. Tindak tutur yang mengancam muka disebut Face-threatening act (FTA), untuk mengurangi keterancaman muka maka penutur dan petutur akan melakukan tindak perlindungan muka face-saving act.

Grice menamakannya sebagai pelanggaran bidal atau maxim. Ada lima jenis pelanggaran maxim, diantaranya adalah flouting a maxim, violating a maxim, infringing a maxim, opting out of a maxim, dan suspending a maxim.

Pelanggaran jenis ini sering dilakukan dengan sengaja oleh penutur. Saat pelanggaran jenis ini dilakukan biasanya penutur dengan sengaja membuat tuturannya lain dengan apa yang dimaksudkan, hal ini membuat petutur harus mampu mencari makna lain atau yang sebenarnya penutur maksudkan. Ada dua kategori pada jenis pelanggaran ini atau Flouting maxim.

Pada pelanggaran kategori ini, dibagi atas beberapa jenis pelanggaran maxim:

1) Flouts exploiting maxim of quality (pelanggaran maxim quality) 
Pelanggaran maxim ini adalah saat penutur tidak mengatakan hal yang sebenarnya.. Selain itu, pelanggaran jenis ini sering digunakan oleh penutur untuk menghindari situasi tutur yang sebenarnya tidak penutur inginkan yaitu dengan cara menuturkan sesuatu yang tidak dapat dibuktikan.

\section{A : What do you do? (apa pekerjaanmu?) \\ B : I'm a teacher. (Guru)}

A : Where do you teach? (dimana anda mengajar?)

B : Outer Mongolia (Di Mongolia sana)

A : Sorry, I asked. (Maaf saya tanya)

2) Flouts exploiting maxim of quantity (pelanggaran maxim quantity)

Pelanggaran maxim ini terjadi saat penutur menuturkan tuturannya terlalu sedikit atau justru berlebih dari apa yang sebenarnya harus dituturkannya.

A : How are we getting there?

B : Well we're getting there in Dave's car.

Secara terang-terangan B memberikan jawaban yang tidak seinformatif yang dibutuhkan oleh A.

3) Flouts exploiting maxim of relation (pelanggaran maxim relation)

Pelanggaran maxim jenis ini terjadi saat penutur menuturkan sesuatu yang tidak relevan dengan yang sedang dibicarakan dalam situasi dan konteks tertentu.

(I finished working on my face. I grab my bag and coat)

Olivia : (I told mother) I was going out

Mother: (she asked where I was Going).

Olivia $\quad$ : (I repeated myself) Out.

4) Flouts exploting the maxim of manner (pelanggaran maxim manner)

Pelanggaran maxim ini terjadi saat penutur menuturkan tuturannya secara samar atau ambigu, sehingga tidak jarang terjadi petutur harus menggali lebih dalam yang dimaksudkan oleh penutur.

Interviewer: Did the united state goverment play any part in Duvalier's departure? Did they, for example, actively encourage him to leave?

Official : I would not to steer you away from that conclusion.

\section{Teori relevansi}

(Sperber, D and Wilson, 1995) mencoba mengevaluasi 3 maxim atau maksim dari Grice. Yang telah melanggar bidal kualitatif, kuantitatif, dan cara tetapi tetap berhasil karena adanya relevansi.

Teori relevansi dikenal juga dengan prinsip relevansi, prinsip ini berisi jaminan penutur, sehingga dapat disimpulkan bahwa:

1. Setiap ujaran mengandung jaminan relevansi penutur yang bonafide menjamin itu.

2. Tugas petutur memahami ujaran penutur dengan mencari relevansinya, untuk itu petutur memperhitungkan konteks (karena kemampuan kognitif setiap orang berbeda)

3. Dalam sebuah percakapan dengan adanya ujaran dalam sebuah situasi munculah sebuah meaning in interaction.

\section{METODOLOGI PENELITIAN}

\section{Pendekatan Penelitian}

Pendekatan yang digunkan dalam penelitan ini adalah kualitatif. Metode penelitian yang digunakan adalah analisis isi karena penelitian ini lebih mengutamakan pendekatan konten dari dialog dalam novel "Asal Kau Bahagia" karya Bernard Batubara. Data percakapan dalam novel dipilih sebagai objek kajian. Alur cerita tersebut sangat mudah dipahami dan ringan untuk dinikmati, ceritanya sangat menyentuh dan memberikan pesan moral yang cukup dalam yaitu pentingnya sebuah kejujuran dalam terutama perasaan. Alasan lain penulis memilih novel ini karena banyak ditemukan berbagaijenis pelanggaran maksim, oleh karena itu penulis memilih percakapan dalam novel tersebut sebagai sumber data.

\section{Penyediaan data}

Menurut Sudaryanto (Sudaryanto, 2015) ada dua metode penyediaan data yaitu metode simak dan cakap. Pada penelitian ini penulis menggunakan metode simak untuk proses penyediaan data. Metode ini dipilih karena objek yang diteliti berupa teks yang berupa dialog. Untuk menerapkan metode tersebut penulis menggunakan teknik catat untuk 
mencatat tuturan dalam dialog yang mengandung praanggapan.

\section{Prosedur}

Sumber data penulisan ini adalah novel "Asal Kau Bahagia" yang ditulis oleh Bernard Batubara prosedur penyediaan data dimulai dengan membaca novel, mengidentifikasi tuturan yang mengandung praanggapan lalu mengelompokannya berdasarkan tipe praanggapan.

Dari data tersebut, penulis mengelompokan terlebih dahulu tuturan-turan yang mengandung peanggaran maksim. Setelah data terkumpul semua lalu dikelompokan masing-masing berdasarkan maksud dari pelanggaran tersebut, setelah itu dideskripsikan dan dijelaskan yang muncul.

\section{HASIL DAN PEMBAHASAN}

Disini penulis akan membahas pelanggaran maxim yang ada dalam tiap percakapan dari para karakter dalam novel "Asala Kau Bahagia" lalu mencoba menggali makna atau tujuan dari tiap implikatur yang muncul dari percakapan tersebut.

Tabel 1. Data 5 Pelanggaran maxim Quantity

\begin{tabular}{ccccc}
\hline \multirow{2}{*}{ DATA } & \multicolumn{4}{c}{ PELANGGARAN MAXIM } \\
\cline { 2 - 5 } & Quantity & Quality & Relev & Manner \\
\hline 16 & 6 & 6 & 1 & 3 \\
\hline
\end{tabular}

Situasi tutur berada di ruang ICU tempat raga Radha terbaring koma.

Papa Radha $\quad$ Dokter Endra, kapan anak saya
bisa sadar Dok?

Mama Radha : Iya, sampai kapan Radha akan seperti ini, Dok?

Dokter : kita evaluasi dulu ya, bapak dan ibu harap tenang dan bersabar. Kita akan terus pantau kondisi Radha...

Konteks tuturan ini adalah saat papa, mama Radha, dan Dokter di ruang ICU yang sedang memantau perkembangan Radha yang semakin tidak menentu. Kondisi tersebut terjadi karena kecelakaan yang dialami Radha saat akan menemui Tasya kekasihnya. Tuturan mama Radha "Iya, sampai kapan Radha akan seperti ini, Dok?" melupakan luapan kecemasannya yang menanti kepastian kondisi Radha untuk berapa lama lagi akan pulih dan tersadar dari koma. Namun dokter juga tidak dapat memberikan kepastiannya karena masih dalam pantauan dan observasi yang memerlukan pengamatan intensif. Dokter memberikan jawabannya dengan bertutur "kita evaluasi dulu ya, bapak dan ibu harap tenang dan bersabar. Kita akan terus pantau kondisi Radha....".

Saat mama Radha bertutur "Iya, sampai kapan Radha akan seperti ini, Dok?" dokter merespon tidak langsung menjawab apa yang ditanyakan oleh mama Radha dengan bertutur "kita evaluasi dulu ya, bapak dan ibu harap tenang dan bersabar. Kita akan terus pantau kondisi Radha....". Tuturan mama Radha mengacu pada "sampai kapan atau waktu tertentu" yang membutuhkan jawaban berupa kepastian waktu detik, menit, jam, hari, bulan, tahun. Namun tuturan dokter berupa pernyataan yang bersifat himbauan agar papa dan mama Radha untuk lebih tenang dan bersabar.

Tuturan dokter tersebut tidak menjawab apa yang ditanyakan oleh penutur yaitu mama Radha maka tuturan tersebut telah melanggar maxim quantity yaitu terkesan berlebih dan justru kurang informatif sehingga justru menambah kecemasan dihati kedua orang tua Radha. Hal ini merujuk pada tuturan dokter "kita evaluasi dulu ya" dan "Kita akan pantau terus" dan juga kondisi Radha yang memang masih kritis dan koma. Keadaan ini mengindikasikan bahwa kondisi Radha belum normal ada beberapa kemungkinan dapat terjadi selama dalam pantauan tim dokter. Dengan demikian tuturan dokter telah melanggar maxim quantity. Pelanggaran yang sama juga terjadi pada data 2, 9, 11, 12, 16 .

\section{Data 7 Pelanggaran maxim Quality}

Siatusi tutur ini terjadi di rumah sakit tepatnya ruang ICU tempat Radha terbaring koma.

Mama Radha : Terima kasih ya Tasya. Tante bersyukur banget Radha punya kamu, Tante ga kebayang kalo Radha sama orang selain kamu.

Tasya

: kita sama-sama doa supaya Radha cepat siuman ya tante....

Selama menjalani hubungan Radha dan Tasya sudah sangat dekat dengan keluarga masing-masing. Begitupun dengan mama Radha yang sudah sangat setuju atas hubungan tersebut. Hingga sebelum kecelakaan tersebut terjadi, berawal dari janji bertemu keduanya di sebuah resto namun Radha ketiduran. Namun mama Radha mengingatkan anaknya tentang janji tersebut, akhirnya Radha dengan tergesa-gesa menyetir untuk segerabertemu Tasya dan kecelaan itu terjadi. Hal ini membuktikan bahwa mama Radha sudah sangat dekat dan mengetahui apa yang akan mereka berdua lakukan hingga waktu nge-date merekapun mama Radha mengetahuinya. 
Setelah kecelakaan tersebut terjadi, Radha koma namun dengan kondisi tersebut justru Radha menjadi tau sebuah rahasia perselingkuhan yang Tasya lakukan. Janji bertemu sebelum terjadi kecelakaan tersebut merupakan waktu dimana Tasya ingin memutuskan hubungan dengan Radha. Oleh karena selama Radha terbaring koma perasaan Tasya bercampur antara cemas, sedih dan penyesalan ats rasa bersalah karena dia telah berselingkuh dari Radha bahkan tepan dihari jadian mereka Tasya ingin putus dari Radha. Saat mama Radha bertutur "Terima kasih ya Tasya, Tante bersyukur banget Radha punya kamu, Tante ga kebayang kalo Radha sama orang selain kamu". Melalui tuturan tersebut, Tasya merasa tertampar karena ternyata Tasya tidak sebaik dan setulus yang mama Radha sangkakan. Tasya bingung harus merespon seperti apa, maka Tasya hanya mampu bertutur "kita sama-sama doa supaya Radha cepat siuman ya tante...”. jelas terlihat dari tuturan Tasya bukan merupakan respon atas pernyataan mama Radha.

Tuturan mama Radha Terima kasih ya Tasya, Tante bersyukur banget Radha punya kamu, Tante ga kebayang kalo Radha sama orang selain kamu". Merupakan tuturan yang sangat tulus dari mama Radha pada Tasya namun Tasya tidak meresponnya dengan baik, justru Tasya berusaha mengalihkan pembahasannya pada kondisi Radha "kita samasama doa supaya Radha cepat siuman ya tante...". Melalui tuturan ini Tasya tidak ingin merespon lebih jauh atas pernyataan mama Radha yang menyanjung dirinya sebagai kekasih yang baik dan setia menemani bahkan saat Radha koma. Hal ini karena Tasya merasa bahwa dia sudah mengkhianati anaknya yaitu Radha.

Tuturan Tasya yang berusaha mengalihkan pembicaraan menggambarkan dia tidak ingin melanjutkan pembahasan tentang hal kebaikan dan kesetiaannya pada Radha. Hal ini dilatarbelakangi oleh kenyataan lain yaitu Tasya telah berselingkuh dari Radha. Tuturan Tasya telah melanggar maxim Quality dengan pengalihan topik pembicaraan. Pelanggaran maxim quality juga terjadi pada data 1 , $3,13,14,15$

\section{Data 8 Pelanggaran maxim manner}

Situasi tutur ini terjadi di lorong menuju roof top rumah sakit, Radha mengajak Andit pergi ke rooftop untuk memberitahukan bahwa dia sedang dalam koma dan rohnya dapat berkomunikasi hanya dengan orang tertentu yang memiliki kemampuan khusus termasuk Andit.

$$
\begin{array}{ll}
\text { Andit } & \text { : mau kemana sih? } \\
\text { Ibu-ibu tua } & \text { : kamu ini engga diajarin sopan } \\
& \text { santun ya? Hah? }
\end{array}
$$
Andit : eh, maaf bu maaf. Maksud saya bukan ibu...
Radha : lo katanya mau cari cewe, lagian bukannya lo diem-diem suka cewe yang lebih tua?

Andit : ini sih bukan tua lagi bro, uzur bro!

Ibu-ibu tua : dasar anak kurang ajarr!

Andit : ampun bu, ampun!

Tuturan diatas terjadi di lorong menuju rooftop rumah sakit. Saat itu Radha mengajar Andit untuk berbicara tentang roh rada yang mampu berkomunikasi dengan Andit. Radha meminta bantuan pada Andit untuk dapat berkomunikasi dengan Tasya. Radha ingin meminta penjelasan Tasya tentang hubungannya dengan Eric yang dia lihat dengan rohnya di sebuah coffee shop. Dengan kondisi dan keadaan yang diluar nalar, maka saat Andit dan Radha bercakap di lorong memancing rasa heran orang-orang yang melintas disitu. Ada yang menganggap Andit tidak waras karena terlihat berbicara dan tersenyum sendiri.

Saat mereka berpapasan dengan ibu tua bertepatan dengan Andit bertutur "mau kemana sih?" ibu tua lagsung merespon dengan bertutur "kamu ini engga diajarin sopan santun ya? Hah?" Radha tertawa dan Andit terkejut segera ia meminta maaf "eh, maaf bu maaf. Maksud saya bukan ibu...". Radha melanjutkan becandaanya dengan bertutur "lo katanya mau cari cewe, lagian bukannya lo diemdiem suka cewe yang lebih tua?" merasa terpancing dengan tuturan Radha, tanpa memperhatikan sekeliling Andit bertutur "ini sih bukan tua lagi, uzur bro!" ibu tua mendengarnya dan langsung memukul Andit dengan tasnya.

Tuturan Andit “mau kemana sih?” menjadi tuturan samar karena Andit tidak menyebutkan subjek yang dia ajak berbicara. Meskipun dia sedang berbicara dengan Radha, namun Andit lupa bahwa Radha tidak kasat mata, jadi jika dilihat secara awam Andit seperti sedang berbicara sendiri. Ternyata saat bertutur melintas ibu tua, terjadilah salah paham. Ibu tua tersebut bertutur "kamu ini engga diajarin sopan santun ya? Hah?" berpikir Andit tidak sopan berbicara dengan sosok yang lebih tua tanpa menyebut subjeknya. Ibu tua tersebut marah, segera Andit bertutur "eh, maaf bu maaf. Maksud saya bukan ibu..." Tuturan samar kembali dituturkan Andit "ini sih bukan tua lagi bro, uzur bro!". Diluar dugaan ternyata tuturan Andit kembali terdengar oleh ibu tua tadi "dasar anak kurang ajarr!"

Kedua tuturan Andit terasa samar karena Andit tidak menyebutkan subjek atau pada siapa tuturannya 
ditujukan maka terjadi salah paham. Meskipun pada situasi di atas jelas bahwa Andit dan Radha sedang berbuncang berdua, namun Andit lupa bahwa raga Radha hanya dapat dilihat olehnya. Maka tuturan Radha menjadi tuturan yang ambigu atau samar. Dalam konteks tuturan diatas melanggar maxim manner yang menjadikan tuturan samar. Pelanggaran jenis ini juga terdapat pada data 4 dan 10.

\section{KESIMPULAN}

Berdasarkan hasil analisa percakapan dari buku "Asal Kau Bahagia" karya Bernard Batubara pelanggaran maxim quantity dan quality paling sering terjadi pada percakapan yang ada di dalamnya. Pelanggaran Quantity terjadi saat penutur maupun petutur memberikan informasi terlalu singkat atau bahkan berlebih dari yang dibutuhkan. Hal ini bertujuan untuk memberikan informasi lebih lengkap pada petutur. Sedangkan pelanggaran maxim quality terjadi saat penutur ingin menghindari situasi tutur yang ada lalu segera ia ganti dengan tuturan lain. Pelanggaran maxim berikutnya yaitu maxim relevance, saat maxim ini dilangggar biasanya penutur akan menuturkan sesuatu yang sangat jauh berbeda dari apa yang ditanyakan, hal ini mendorong petutur untuk dapat menarik benang merah atas apa yang tersirat dari tuturan tersebut yang didasari oleh persamaan pengetahuan atau knowledge background. Sedangkan untuk pelanggaran maxim quality terdapat beberapa data yang mengandung pelanggaran tersebut. Berikutnya maxim manner yaitu penutur mencoba menuturkan sesuatu dengan samar hingga menimbulkan ambiguity. Dalam buku
“Asal Kau Bahagia” Tuturan ini terkadang membuat kesalahpahaman antara penutur dan petutur.

\section{REFERENSI}

Grice, H. . (1975). "Logic and Conversation". Syntax and Semantics, Speech Act, 3. New York: Academic Press.

Nadar, F. . (2009). Pragmatik \& Penelitian Pragmatik. Yogyakarta: Graha Ilmu.

Purwaningrum, P. W. (2019). Pelanggaran Maxim Dalam Novel Asal Kau Bahagia Karya Bernard Batubara. 2Wanastra, 11(2), 107112.

Purwo, B. K. (1984). Deiksis dalam Bahasa Indonesia. Jakarta: Balai Pustaka.

Sperber, D and Wilson, D. (1995). A Relevance.Communication and Cognition. Cambridge: Cambridge University Press.

Sudaryanto, S. (2015). Metode dan Aneka Teknik Analisa Bahasa: Pengantar Penelitian Wahana Kebudayaan Secara Linguistis. Yogyakarta: Sanata Dharma University Press. 